\title{
ASSÉDIO MORAL NAS ORGANIZAÇÕES E SEUS IMPACTOS
}

MORAL HARASSMENT IN ORGANIZATIONS AND ITS IMPACTS

\author{
LUCY MORAES DE MARAZZO ${ }^{1}$ \\ MARCELO JASMIM MEIRIÑO ${ }^{2}$ \\ MIRIAN PICININI MÉXAS ${ }^{3}$ \\ FÁBIO GOULART VILLELA ${ }^{4}$ \\ GEISA MEIRELLES DRUMOND ${ }^{5}$
}

RESUMO: Diante das inúmeras denúncias de assédio moral e outros atos de violência no trabalho, faz-se relevante a pesquisa sobre o assédio moral nas relações de trabalho, para produzir e disseminar conhecimento sobre o tema, além de captar medidas de prevenção com base na percepção dos trabalhadores. O objetivo geral desta pesquisa é propor ações preventivas para coibir o assédio moral no ambiente organizacional. A metodologia utilizada foi a pesquisa exploratória e qualitativa, sendo realizada com 30 especialistas que responderam um questionário com 10 atitudes, que foram replicadas, usando 2 escalas valorativas (frequência e grau de impacto) e uma questão aberta. Observou-se que as atitudes de assédio moral, que foram elencadas no questionário, acontecem com certa frequência no ambiente de trabalho, confirmando a visão de autores sobre alguns comportamentos que tipificam o assédio moral. Quanto ao impacto das atitudes de assédio moral, evidenciou-se que quase todas as atitudes demonstraram impacto significado no ambiente organizacional. Além disso, indicaram-se algumas propostas para combater as manifestações do assédio moral no ambiente de trabalho. Recomenda-se, com base nos resultados obtidos, a realização de estudos futuros que enfoquem a questão do assédio moral em determinadas áreas de atuação no serviço público.

Palavras-chave: Assédio moral; Ambiente Organizacional; Relações de trabalho.

ABSTRACT: Faced with numerous complaints of harassment and other acts of violence at work, it is important to research on moral harassment in labor relations, to produce and disseminate knowledge on the subject, in addition to capture prevention measures based on the perception of workers. The overall objective of this research is to propose preventive actions to curb moral harassment in the organizational environment. The methodology used was exploratory and qualitative research, being conducted with 30 experts who replied a questionnaire with 10 actions, which were replicated using 2 scales evaluative (frequency and degree of impact) and an open question. It was observed that the attitudes of moral

\footnotetext{
Data de submissão: 18/01/2017 Data de aceite: 06/04/2018 Data de publicação:

${ }^{1}$ Mestre em Sistema de Gestão pela Universidade Federal Fluminense. Psicóloga Organizacional com especialização em Gestão de Recursos Humanos.

2 Doutor em Engenharia Civil pela Universidade Federal Fluminense.

Professor da Universidade Federal Fluminense.

${ }^{3}$ Doutora em Engenharia Civil pela Universidade Federal Fluminense

Professora da Universidade Federal Fluminense.

${ }^{4}$ Procurador do Trabalho da 1a Região.

${ }^{5}$ Mestre em Sistema de Gestão pela Universidade Federal Fluminense.
} 
harassment, which were listed in the questionnaire, occur with some frequency in the workplace, confirming the author's view of some behaviors that typify moral harassment. Referring to the impact of moral harassment attitudes, it showed that almost all the attitudes demonstrated significance impact in the organizational environment. Moreover, some proposals were indicated to combat the manifestations of moral harassment in the workplace. It is recommended, based on the research results, future studies that address the issue of moral harassment in certain areas of activity in public service.

Keywords: Moral harassment; Organizational environment; Labor relations.

\section{INTRODUÇÃO}

As denúncias de assédio moral e outros atos de violência no trabalho vêm crescendo a cada dia na Justiça do Trabalho em nosso país, sendo denunciados por sindicatos, pelo próprio trabalhador e muitas vezes a arbitrariedade é tamanha que a Procuradoria Regional do Trabalho propõe uma ação civil pública para proteger os trabalhadores.

Uma vez que o assédio moral se caracteriza por condutas antiéticas que expõem o trabalhador a situações constrangedoras e humilhantes, de maneira intencional e reiterada por certo tempo no ambiente de trabalho, tais abusos lesam a dignidade da pessoa humana, sendo repudiados pelos princípios e regras constitucionais, por estarem em desacordo com valores intrínsecos a todo ser humano.

Percebe-se que alguns locais de trabalho, cada vez mais, se configuram num palco de arbitrariedades e desrespeito ao trabalhador, contrariando não só as mais elementares regras do convívio social, mas as determinações do próprio contrato de trabalho.

Um ambiente de humilhações e sofrimento quebra a rede de trabalho digno como prioriza a Agenda Nacional de Trabalho Decente (2006), sendo a prática do assédio moral uma afronta à dignidade da pessoa humana pela violação aos direitos humanos.

Em conformidade com o problema apresentado, torna-se relevante a pesquisa sobre o assédio moral nas relações de trabalho, para produzir e disseminar conhecimento sobre o tema, além de captar medidas de prevenção com base na percepção dos trabalhadores. Sendo assim, o objetivo geral deste estudo é propor ações preventivas para coibir o assédio moral no ambiente organizacional.

\section{FORMAS DE MANIFESTAÇÃO DO ASSÉDIO MORAL}

Existem vários comportamentos que o assediador pode fazer uso para agredir o trabalhador, dentre eles estão as ações visíveis que expõem os trabalhadores a situações humilhantes e as ações invisíveis, dissimuladas, ambíguas presentes muitas vezes de forma imperceptível no ambiente de trabalho.

Paroski (2006) diz que a conduta que causa o assédio moral não necessita ser explícita, manifestando-se de forma velada, através de gestos sutis e palavras equívocas, justamente para dificultar sua identificação. $O$ assediador demonstra, na maioria dos casos, preferência pela manifestação não verbal de sua conduta, para dificultar o desmonte de sua estratégia, bem como, o revide pela vítima. 
As ações invisíveis na visão de Parreira (2007) são percebidas somente pela vítima, pois é para o alvo que o perverso revela sua face oculta.

A exteriorização do assédio moral também pode ocorrer somente sob a forma de manobras veladas, classificadas como 'técnicas de infernização': gestos, sorrisos, suspiros, erguer de ombros, olhar de desprezo, silêncio, críticas indiretas, subentendidos malévolos, indiferença à presença e/ou existência do agente passivo, silêncio forçado, menear da cabeça em sinal de discordância ou desaprovação, até murmurar 'tsc, tsc, tsc' rapidamente durante a aproximação e o afastamento da vítima. [...] Com a repetição desses momentos de zombaria, de gestos e olhares, pode-se afetar profundamente a paz de espírito que os trabalhadores precisam no seu dia a dia (PARREIRA, 2007, p. 22).

Portanto, através de ações invisíveis é possível cometer um grave dano psíquico e moral no trabalhador.

Segundo a Organização Internacional do Trabalho (2003), o assédio moral é um tipo de comportamento que tem como objetivo desqualificar, humilhar e rebaixar, através de meios vingativos, cruéis, maliciosos e de críticas repetitivas e desqualificações, uma pessoa ou um grupo de trabalhadores (SOBOLL, 2006).

No entanto, é preciso frisar que nem toda situação de violência ou agressão psicológica no trabalho é tipificada como assédio moral. A repetitividade e intencionalidade são os elementos que caracterizam o assédio moral e o diferenciam das agressões psicológicas pontuais e dos conflitos nas relações interpessoais.

Segundo Soboll e Gosdal (2009), dentre os comportamentos mais apresentados quando o assunto é violência psicológica, destacam-se a constante imposição para atingir metas induzindo rivalidade sem observação de ética; o controle freqüente; o emprego de estratégias cerceantes; a confrontação entre membros da mesma equipe; a avaliação do desempenho sem observação de métodos e validando apenas a conseqüência; a ameaça constante de demissão e a degradação dirigida ao grupo de trabalhadores que não atingem o resultado esperado.

\section{ASSÉDIO MORAL E ASPECTOS LEGAIS}

No ordenamento jurídico brasileiro o assédio moral ainda não foi tipificado como crime, embora existam várias leis municipais e estaduais que protegem o servidor público em alguns Estados, o que significa que o trabalhador não está desamparado.

As convenções, pactos e tratados internacionais que foram ratificadas pelo Brasil trazem embasamento legal em defesa do Ser humano, pois antes de ser trabalhador, o indivíduo é Ser Humano, sendo esse o principal argumento para coibir a prática de assédio moral.

A Declaração Universal dos Direitos Humanos (1948) assevera que "todos os seres humanos nascem livres e iguais em dignidade e direito" (art. I) e "toda a pessoa tem direito ao trabalho, à livre escolha do trabalho, a condições equitativas e satisfatórias de trabalho e à proteção contra o desemprego" (art. XXIII, 1).

O Pacto Internacional sobre Direitos Econômicos, Sociais e Culturais (1992) afirma: 
As medidas que cada Estado Parte do presente Pacto tomará a fim de assegurar o pleno exercício desse direito deverão incluir a orientação e a formação técnica e profissional, a elaboração de programas, normas e técnicas apropriadas para assegurar um desenvolvimento econômico, social e cultural constante e o pleno emprego produtivo em condições que salvaguardem aos indivíduos o gozo das liberdades políticas e econômicas fundamentais (art.VI, 2).

A Convenção Americana de Direitos Humanos (1969), Pacto de San José da Costa Rica, no art. 5o certifica que:

1. Toda pessoa tem direito a que se respeite sua integridade física, psíquica e moral.

2. Ninguém deve ser submetido a torturas, nem a penas ou tratos cruéis, desumanos ou degradantes. Toda pessoa privada de liberdade deve ser tratada com o respeito devido à dignidade inerente ao ser humano.

A Convenção n. 111 (1958) da Organização Internacional do Trabalho define como discriminação no emprego e profissão "toda distinção, exclusão ou preferência fundada na raça, cor, sexo, religião, opinião política, ascendência nacional ou origem social, que tenha por efeito destruir ou alterar a igualdade de oportunidade ou de tratamento em matéria de emprego ou profissão".

No art. 3o da Convenção n. 155 (1981) da Organização Internacional do Trabalho, o termo 'saúde' com relação ao trabalho abrange não só a ausência de afecções ou de doenças, mas também os elementos físicos e mentais que afetam a saúde e estão diretamente relacionados com a segurança e a higiene no trabalho.

Percebe-se que diante dos tratados internacionais ratificados pelo Brasil, não falta fundamento legal para coibir a prática do assédio moral nas relações de trabalho.

Já a constituição Federal de 1988 traz a proteção contra o assédio moral:

Art. 10 A República Federativa do Brasil, formada pela união indissolúvel dos Estados e Municípios e do Distrito Federal, constitui-se em Estado Democrático de Direito e tem como fundamentos: III - a dignidade da pessoa humana; IV - os valores sociais do trabalho.

Art. 4ำ A República Federativa do Brasil rege-se nas suas relações internacionais pelos seguintes princípios: II - prevalência dos direitos humanos;

Art. 5o Todos são iguais perante a lei. X - são invioláveis a intimidade, a vida privada, a honra e a imagem das pessoas, assegurado o direito à indenização pelo dano material ou moral decorrente de sua violação.

A Consolidação das Leis Trabalhistas (CLT) é a responsável pelas normas legislativas referentes ao Direito do Trabalho e do Direito Processual do Trabalho no Brasil. No artigo 483 há previsão de interrupção do vínculo trabalhista com direito as verbas rescisórias caso o empregado se sinta vítima dos casos determinados pela lei, muitos deles são casos de assédio (CLT, 2007). 
Nascimento (2015) acrescenta que alguns países já possuem legislação específica sobre o assédio moral, como a Suécia, a França, a Noruega, a Finlândia, Argentina e a Austrália. Nos Estados Unidos, os casos de assédio são julgados de acordo com a legislação de dano moral (The Civel Right Act/1964). Há outros em que há apenas Projetos de Lei. São eles: Espanha, Itália, Japão, Portugal, Suíça, Bélgica, Uruguai e Brasil.

\section{ESTUDOS SOBRE ASSÉDIO MORAL NO CENÁRIO INTERNACIONAL}

O tema assédio moral tem despertado o interesse de vários pesquisadores ao redor do mundo. Pode-se constatar com base na revisão de literatura que os trabalhos sobre esse tema são tratados dentro de uma perspectiva da saúde do trabalhador, além de serem evidenciadas abordagens sobre metodologias de estudo sobre o assédio moral e as delimitações conceituais, os determinantes e as consequências desse fenômeno, bem como as formas de intervenção para prevenção do assédio moral no trabalho.

Destaca-se o estudo de Neall e Tuckey (2014) sobre uma revisão metodológica para identificar lacunas atuais e propor novas estratégias para o avanço do conhecimento sobre o assédio no trabalho. Para atingir esse objetivo, realizou-se uma revisão sistemática de uma gama de questões metodológicas que podem minar a validade de estudos, concentrando-se na pesquisa sobre antecedentes e resultados de assédio moral. Nesse estudo, foram considerados artigos de periódicos revisados por pares, recuperados nas bases PsyINFO e PubMed, no período de 1987 a 2012. Do total de 1083 artigos disponíveis nas bases, obtiveram-se 224 artigos de revisão, após a adoção de critérios de inclusão. Os métodos de coleta de dados e os instrumentos de medição quantitativa utilizados em cada estudo foram codificados como ameaças potenciais para construir validade. As questões relacionadas com a validade interna dos estudos também foram documentadas e são decorrentes do projeto, configuração e níveis de controle evidente nos estudos. Quanto à validade externa, as questões metodológicas referem-se à origem dos participantes por país, a população do estudo e a representatividade da amostra. Os aspectos da coleta de dados e do processo de análise, que podem afetar as conclusões do estudo, foram codificados sob a validade da conclusão estatística, e incluem a proposta de cada estudo, que é referente aos antecedentes e às consequências do assédio moral no trabalho, à combinação dos dois ou ao processo de assédio; ao nível de análise; à triangulação dos dados ou múltiplas fontes de dados e às técnicas utilizadas para analisar os dados.

Com base nos resultados, identificou-se que mais da metade dos estudos analisados sobre assédio moral foi conduzida com trabalhadores nos Estados Unidos e em países de língua inglesa (Reino Unido, Austrália e Canadá) enquanto países escandinavos e da Europa Ocidental (Noruega, Finlândia, Bélgica, Dinamarca e Suécia) correspondem a 1/5 dos estudos da revisão. Observou-se que os estudos sobre os resultados e antecedentes do assédio no local de trabalho compõem a maior parte da pesquisa na área. Os resultados da análise também revelaram que a maioria das pesquisas de assédio tem sido conduzida a nível individual, além de não relatar sobre o autor ou a fonte do assédio. Em relação às técnicas de análise de dados, mais da metade das pesquisas relataram o uso de estatística inferencial simples. Identificou-se também a forma qualitativa de análise de dados. Quanto à validade de constructo, observou-se que o assédio normalmente tem sido avaliado através de uma lista de verificação comportamental e poucos estudos fornecem uma definição de assédio 
aos participantes. A ameaça à validade interna foi identificada como decorrente de estudos transversais com dados fornecidos por apenas uma fonte e analisados a nível individual. Os autores consideram que para aumentar a validade interna, deve-se realizar estudos longitudinais para aumentar a confiança sobre as relações causais entre assédio moral, seus antecedentes e consequências. (NEALL; TUCKEY, 2014).

Do mesmo modo, a pesquisa que investiga a exposição, antecedentes e os efeitos do assédio moral, seguindo o curso de tempo do desenvolvimento nos trabalhadores, é extremamente necessária e irá melhorar a validade da conclusão estatística de investigações futuras sobre o assédio moral. As limitações quanto à validade externa foram evidenciadas quanto à falta de relatórios referentes à população em estudo e à representatividade da amostra (NEALL; TUCKEY, 2014). Este estudo trouxe como contribuição recomendações para avanços em métodos de investigação na área do assédio moral de modo a melhorar a validade dos mesmos e assim progredir nos esforços de prevenção e desenvolvimento da teoria. Na visão desses autores, obter melhorias da medição de assédio permitirá que os pesquisadores descubram diferentes processos no desenvolvimento de assédio para que possam ser implementadas diretrizes de prevenção mais eficazes.

Em Múrcia, na Espanha, desenvolveram-se estudos para avançar nas investigações sobre assédio moral no trabalho. Nessas investigações priorizaram-se as questões sobre a delimitação do conceito, as formas de quantificação, a prevalência, a procedência das condutas de assédio moral, os determinantes pessoais e organizacionais, as consequências e a autoeficácia, que pode moderar os efeitos das condutas de assédio moral, além das principais formas de intervenção, considerando-se também as ações adequadas de prevenção (GARCIA-IZQUIERDO et al., 2014). Através desses estudos, pode-se constatar que o assédio moral é um fenômeno heterogêneo, que se manifesta de modos diferentes e que pode ser compreendido como um único processo contra uma pessoa ou como uma estratégia para alcançar os objetivos da organização, juntamente como uma forma de exercer controle sobre os trabalhadores.

Os antecedentes para ocorrência do assédio moral estão relacionados com fatores psicossociais na organização e ambiente de trabalho, dentre eles: conflito, ambiguidade de papel, sobrecarga de trabalho contínuo, pressão no trabalho, alta carga de trabalho mental, certos estilos de liderança e formas de gestão (GARCÍA-IZQUIERDO et al., 2014). Quanto às consequências, o assédio moral causa muitos danos à saúde, como problemas psicológicos, psicossomáticos e músculo-esqueléticos. Em outros estudos abordados por García-Izquierdo et al. (2014), observou-se o absenteísmo como uma das consequências do assédio moral, estando associado com causas naturais (acidentes de trabalho) e psicológicas (depressão e ansiedade).

Os determinantes pessoais também contribuem para a percepção de níveis de estresse e desconforto associados ao assédio moral. Essas variáveis pessoais são determinantes na forma como os indivíduos reagem às situações de assédio. Os resultados de vários estudos sugerem que as características individuais são importantes na resposta às situações de assédio moral e podem explicar, pelo menos em parte, os efeitos sobre a saúde. Nesse âmbito, realizou-se um estudo sobre o papel da autoeficácia, que foi apontada como um recurso pessoal que ajuda as pessoas a lidar com situações de estresse e a proteger a sua saúde (GARCÍA-IZQUIERDO et al., 2014). 
Segundo García-Izquierdo et al. (2014), a intervenção para controle e prevenção do assédio moral é considerada um tema polêmico, devido à complexidade daquele fenômeno. Do ponto de vista organizacional, a correta aplicação dos procedimentos de Recursos Humanos desempenha um papel essencial. Nesse âmbito, considera-se necessária a análise e resolução de conflitos em todos os níveis hierárquicos, bem como o acompanhamento das ações implementadas com esse objetivo. Os programas de assistência para os funcionários, como aconselhamento e apoio às vítimas de violência no trabalho, e a definição de uma política organizacional sobre esse tipo de violência, acompanhada de medidas disciplinares severas no caso de violação, são fundamentais para garantir a saúde ocupacional e o bem estar dos trabalhadores. Tais medidas devem estar focadas principalmente na prevenção desse fenômeno nas organizações.

García-Izquierdo et al. (2014) ainda sugerem alguns temas de estudo sobre o assédio moral, como: os perfis que descrevem as vítimas e assediadores; as características de trabalho que conduzem a um risco maior de assédio; o tipo de relacionamento entre o agressor e a vítima no contexto de trabalho; o papel das testemunhas e observadores do fenômeno; a atitude e o comportamento dos gestores e das pessoas envolvidas nessa situação; as estratégias mais eficazes de avaliação e de prevenção, além da avaliação de protocolos para agir contra o assédio moral.

No estudo desenvolvido por Meseguer, Soler e García-Izquierdo (2014), analisou-se a relação entre a autoeficácia profissional, a exposição a comportamentos de assédio no trabalho e a saúde, onde algumas hipóteses foram formuladas buscando confirmar a relação existente entre elas. Participaram da pesquisa 772 trabalhadores, que exerciam atividades em vários ramos profissionais. Para medir o assédio no trabalho, a autoeficácia profissional e avaliar a saúde foram utilizados: a escala Negative Acts Questionnaire (NAQ); a subescala Maslach Burnout Inventory General Survey (MBI-GS) e o Questionário Geral de Saúde General Health Questionnaire (GHQ-12), respectivamente. Com base nos resultados obtidos, as hipóteses formuladas foram confirmadas e referem-se à existência de relações significativas entre autoeficácia profissional e a capacidade dos indivíduos em responder as condutas de assédio no trabalho, podendo exercer algum controle sobre elas. Esse estudo evidenciou o papel moderador da autoeficácia profissional sobre a saúde em situações de assédio.

A avaliação da taxa de prevalência de assédio moral no trabalho entre funcionários no Japão foi tema do estudo realizado (GIORGI et al., 2013). Nesse estudo, participaram efetivamente 699 funcionários recrutados em sindicatos na região de Tóquio. O método utilizado, conhecido como método de autorrotulagem consistiu em fornecer aos participantes uma definição de assédio moral para que eles indicassem se tinham ou não sofrido assédio nos últimos 6 meses, além de completarem alguns itens referentes a sexo, status de trabalho, estado civil e tendência à depressão. Observou-se que a taxa de prevalência de assédio moral no trabalho foi de $15 \%$, sendo que o nível de percepção sobre situações de assédio foi mais elevado no sexo feminino. Além disso, verificou-se a associação positiva entre a depressão e a percepção do assédio, enquanto a coesão da equipe, o apoio do supervisor e o clima orientado para inovação tiveram uma associação negativa com o assédio. $O$ presente estudo demonstrou a importância de se considerar as diferenças individuais nas situações de assédio, além de sugerir que a promoção da saúde mental pode 
ajudar na prevenção do fenômeno, assim como as intervenções organizacionais podem melhorar a coesão do grupo e o clima organizacional.

Shallcross, Ramsay e Barker (2013) debruçaram-se sobre o assédio moral, buscando avançar na compreensão sobre esse tema, incluindo as relações formais e informais de poder com as organizações. Descrevem 5 estágios do processo de assédio moral, que se inicia com o conflito não resolvido até culminar na expulsão da organização. Na sexta fase, inclui-se a capacidade individual para recuperar o poder pessoal frente à situação de assédio. Os objetivos desse estudo referem-se: 1 ) a experiência vivida do assediado no local de trabalho; 2) as ações dos indivíduos através de suas respostas e 3) as medidas tomadas pelas organizações para identificar quaisquer padrões de resposta. Nesse estudo, participaram inicialmente 212 indivíduos, empregados do setor público que concordaram em contribuir para esse estudo e se envolver com o pesquisador através de e-mail no primeiro ano de estudo. No segundo e terceiro anos de estudo, o número foi reduzido para 62 participantes e, posteriormente, 15 participantes foram selecionados para entrevistas. No segundo e terceiro anos de estudo, utilizaram-se documentos validados, incluindo relatórios médicos, roteiros de entrevista, documentos legais, transcrições do tribunal.

Nesse estudo, abordaram-se as conceituações de assédio, além das idéias de assédio moral no trabalho e de diferentes perspectivas de poder e a falta de neutralidade dos sistemas de apoio. 0 presente estudo identificou o assédio moral no local de trabalho como uma forma distinta de violência no trabalho. Com base nas 5 fases do assédio moral, que se caracterizam por estágios progressivamente negativos até a expulsão da organização, buscou-se analisar a contribuição do conflito não resolvido para o processo de assédio no trabalho e, em particular, o papel das diferenciações e aquisição de poder pelas partes envolvidas durante a escalada de conflitos. Discutiram-se as contingências que podem representar pontos de apoio para a intervenção e, finalmente, a prevenção do assédio moral. Apresentaram-se recomendações de melhorias em processos organizacionais e propostas de intervenções, que podem impedir o aparecimento de processos de assédio moral. $O$ estudo trouxe contribuição especial à compreensão das complexidades de resolver conflito e de usar o poder nas organizações (SHALLCROSS; RAMSAY; BARKER, 2013).

A revisão de literatura sobre assédio moral foi o foco do estudo, realizado por Branch, Ramsay e Barker (2013), que identificou comunidades de investigação sobre o assédio na Europa, Austrália, Ásia e Estados Unidos. Através desse estudo de revisão, os autores buscam avançar na compreensão da complexidade do assédio moral no local de trabalho por meio do desenvolvimento de um novo modelo conceitual e da análise de seus elementos inter-relacionados, que expliquem a natureza complexa e dinâmica do assédio moral no local de trabalho, além de enfatizar os debates atuais, lacunas na literatura e direções futuras para pesquisa. O modelo conceitual proposto pelos autores consiste de 7 elementos: 1) a sociedade; 2) o ambiente de trabalho; 3) o aparecimento de eventos afetivos ou assédio moral; 4) a resposta individual e organizacional; 5) o bem-estar individual e organizacional; 6) a eventual continuação de eventos afetivos; e 7) o possível término de eventos afetivos. Esse modelo integrativo contribui para a identificação dos pontos de intervenção que podem minimizar a ocorrência dos eventos afetivos. Apesar desse estudo identificar avanços consideráveis sobre o assédio moral nas últimas décadas, o tema ainda requer muita atenção, indicando-se 4 áreas importantes para futuras pesquisas sobre assédio moral no local de trabalho: 1) a compreensão da definição, incluindo a controversa 
questão dos recursos de poder e sua distribuição; 2) a teoria do assédio moral no local de trabalho; 3) o assédio moral como fenômeno multifacetado, englobando perspectivas ambiental ou de grupo, que ainda é pouco explorado na literatura; e 4) políticas associadas com prevenção e intervenções organizacionais. Esse estudo de revisão trouxe como contribuição um novo modelo integrativo que capta a complexidade do local de trabalho, os processos de assédio moral e fornece um caminho a seguir para pesquisadores e profissionais.

O estudo realizado por Faulx e Blavier (2013) revela que muito poucos estudos foram publicados a partir do ponto de vista das pessoas que vivem situações de assédio. Propõem o modelo Liège para analisar o assédio moral no trabalho, considerando além do ponto de vista da vítima, outros elementos, como o ponto de vista do agressor e as relações em um nível organizacional. Os autores sugerem duas maneiras em que o modelo poderia ser usado em pesquisas futuras: 1) para comparar diferentes situações sob o ponto de vista de um grande número de vítimas e 2) para a realização de análise de casos integrando os pontos de vista de vários atores em uma única situação. Em seu estudo, analisaram um estudo de caso utilizando o modelo Liège, tendo como desafio obter uma melhor compreensão da dinâmica do assédio moral e também discutir os pontos fortes desse modelo em termos de estratégias de diagnóstico e de intervenção. Adotou-se uma abordagem de assédio que utiliza múltiplas perspectivas e que é multidimensional e multitemporal. 0 estudo de caso foi realizado em uma empresa de mídia de impressão que emprega 65 trabalhadores, sendo realizadas entrevistas semidiretivas com 9 pessoas envolvidas em situação de assédio psicológico. $\mathrm{Na}$ análise, considerou-se uma estrutura conceitual de nível múltiplo e a integração das perspectivas de diferentes atores para estudar em que medida os pontos de vista se sobrepõem, se correlacionam ou se contradizem. Na discussão dos resultados, verificou-se que o modelo sofre de algumas limitações relacionadas à integração de mais fatores de risco estrutural e de elementos contextuais mais amplos. Ressalta-se ainda que a análise desse estudo se baseou em diferentes testemunhos, que aumentam a credibilidade e a validade dos dados obtidos. Esse estudo trouxe como contribuição a adoção do modelo Liège, que permite compreender a relação entre o agressor, a vítima, o grupo de pares e os processos de gestão, além de possibilitar a prevenção das situações de assédio moral.

A influência de alguns fatores psicossociais no trabalho, como clareza do papel, conflitos interpessoais e suporte social, sobre o assédio e suas consequências foi tema do estudo realizado por Figueiredo-Ferraz et al. (2012). A partir da composição da amostra de 422 empregados espanhóis, que trabalham com pessoas com deficiência intelectual, e o uso da subescala UNIPSICO para medir os fatores psicossociais e da escala mobbing-UNIPSICO, para avaliar o assédio, que levou em consideração as ações de assédio que são mais freqüentes na Espanha, esse estudo revelou que a ambiguidade do papel, o baixo suporte social e os conflitos interpessoais são determinantes para o assédio. Nesse estudo, todas as hipóteses formuladas foram confirmadas, utilizando-se um modelo de equações estruturais, que foi considerado válido para explicar o desenvolvimento do assédio. De acordo como modelo hipotético, o assédio desempenha um papel mediador entre os fatores psicossociais avaliados e as suas consequências, ou seja, distúrbios psicossomáticos e a inclinação para o absenteísmo.

Além do estudo supracitado, realizou-se na Espanha uma pesquisa usando um conjunto de dados sobre trabalhadores espanhóis do inquérito espanhol sobre condições de 
trabalho, tendo como objetivo estudar o impacto do assédio sobre a saúde dos trabalhadores na Espanha (CARNERO; MARTINEZ; SÁNCHEZ-MANGAS, 2012). O estudo identificou tanto os trabalhadores assediados como aqueles não assediados e utilizou dois indicadores de saúde: a percepção do trabalhador que o trabalho afeta a saúde e a presença de sintomas de saúde precária. Para os autores da pesquisa, esse estudo foi a primeira tentativa de analisar empiricamente a relação entre assédio e saúde nos locais de trabalho. Com base na evidência empírica, os autores formularam um modelo econométrico para quantificar o impacto do assédio moral na saúde. Os resultados mostraram que ser vítima de assédio moral no trabalho aumenta significativamente a probabilidade de perceber que o trabalho afeta a saúde e também a probabilidade de sofrer de sintomas de saúde. Quando o indicador de saúde é a percepção do trabalhador de que o trabalho afeta a saúde foram encontradas evidências da endogeneidade do assédio, o que significa dizer que ser uma vítima de assédio aumenta a probabilidade de relatar que o trabalho afeta a saúde em 50 pontos percentuais. Quanto ao sofrimento com sintomas de saúde, ser vítima de assédio moral aumenta significativamente a probabilidade em cerca de 26 pontos percentuais, em média.

A análise das práticas de exclusão do trabalho italiano e a alienação no contexto do neoliberalismo foram temas do estudo de Molé (2010). Utilizou-se como metodologia a entrevista com ativista sindical e trabalhador oficial do governo, buscando refletir sobre a cidadania italiana, através da análise de antecipação, para compreender os processos psíquicos subjacentes ao neoliberalismo e como eles produzem um regime de ansiedade, paranóia e desconfiança. Conforme as entrevistas, assim como a precariedade promove processos de individuação e isolamento, reconhece-se, também, o bem-estar no trabalho.

\section{METODOLOGIA DA PESQUISA}

O presente estudo se classifica como pesquisa exploratória, tendo como "principal finalidade desenvolver, esclarecer e modificar conceitos e ideias, tendo em vista, a formulação de problemas mais precisos ou hipóteses pesquisáveis para estudos posteriores" (GIL, 1999, p.43), bem como pesquisa qualitativa por ter como característica "a tentativa de uma compreensão detalhada dos significados e características situacionais apresentadas pelos entrevistados" (RICHARDSON, 1999, p.90).

Para compor a revisão de literatura deste estudo, realizou-se um estudo bibliométrico na base Scopus, buscando identificar artigos relacionados ao tema assédio moral, que foram publicados entre 2010 e 2015. No motor de busca, foram utilizadas as palavras-chave: Moral Harassment OR Mobbing AND Workplace. Após leitura criteriosa do título e abstract dos 32 artigos inicialmente selecionados, foram considerados para análise 10 artigos, por serem mais aderentes ao objetivo deste estudo.

Adotou-se como instrumento de pesquisa um questionário, contendo questões fechadas, que foram replicadas usando 2 (duas) escalas valorativas do tipo Likert: frequência e grau de impacto, e uma questão aberta. Os 10 itens das questões fechadas foram propostas com base nos autores: Alkimin (2005), Soboll (2006), Guedes (2008), Ávila (2009), Hirigoyen (2009), Soboll e Gosdal (2009), Araújo (2012) e Calvo (2014).

O questionário foi aplicado em uma amostra de especialistas, assim caracterizados: profissionais com experiência na sua área de atuação, englobando as seguintes áreas: 
Gestão da Responsabilidade Social Organizacional, Gestão de Pessoas, Membros da Justiça do Trabalho e da Saúde do Trabalhador nas organizações. O critério para escolha desses especialistas baseou-se nas competências e no domínio de conhecimentos sobre o tema abordado.

\section{ANÁLISE DOS RESULTADOS}

Inicialmente foram distribuídos 120 questionários com retorno de $25 \%$ de respostas válidas, ou seja, 30 questionários foram respondidos. Considera-se que a taxa de retorno das respostas encontra-se dentro da média, em situações de pesquisas organizacionais, conforme Marconi e Lakatos (2010).

Os questionários foram distribuídos online entre grupos de especialistas que conhecem o tema do assédio moral no ambiente de trabalho, contactados por meio de redes sociais na web, e enviados por e-mail para os especialistas não participantes desses grupos. A aplicação do questionário foi realizada durante o período de dois meses.

\section{Identificação dos respondentes}

Participaram efetivamente da pesquisa 30 especialistas com formação profissional nas áreas de Direito, Psicologia, Administração de Empresas, Serviço Social, Engenharia de Produção, Comunicação Social e Pedagogia, que responderam ao inventário sobre as atitudes de assédio moral em ambiente de trabalho quanto à frequência e ao impacto nas organizações.

A Figura 1 mostra a área de atuação dos respondentes, dividido em duas categorias: publico e privado.

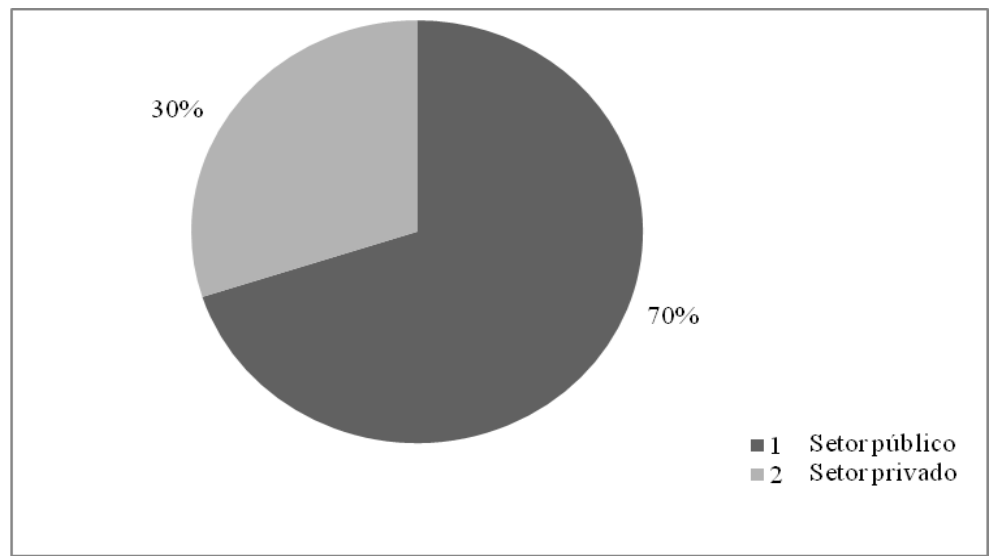

Figura 1 - Área de atuação dos participantes da pesquisa. Fonte: Dados de pesquisa (2016).

Conforme os dados obtidos, a maioria dos respondentes, 70\%, são provenientes do setor público, enquanto $30 \%$ são da iniciativa privada, isso pode indicar uma maior disponibilidade e interesse dos servidores públicos em participar da pesquisa sobre o assédio moral no ambiente de trabalho. Tal fato sugere a estabilidade do funcionário ou servidor 
público, ressaltando a ausência de estabilidade na empresa privada. No entanto, seria, de certa forma, ingênuo acreditar que as atitudes não são idênticas nos dois setores.

A Figura 2 retrata o tempo de experiência dos especialistas, verificando-se que o maior percentual concentra-se entre 10 e 15 anos (34\%), seguido do intervalo de 5 a 10 anos (30\%). Apenas 3\% dos respondentes tinham entre 20 a 25 anos de experiência.

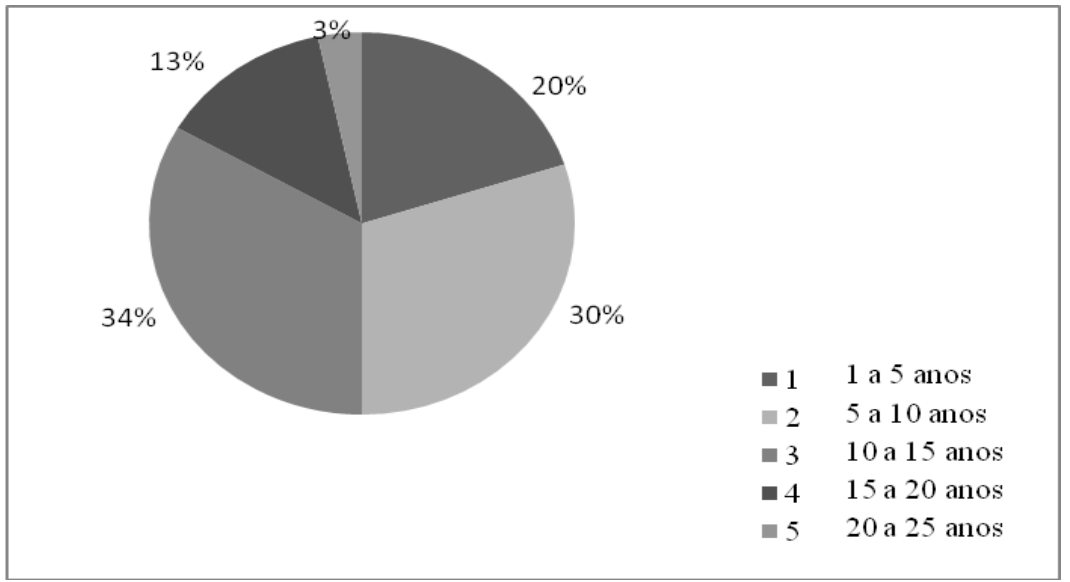

Figura 2 - Tempo de experiência dos especialistas.

Fonte: Dados de pesquisa (2016).

A seguir, analisaram-se os 10 itens do questionário fechado, conforme escala Likert proposta.

\section{Frequência das práticas de assédio moral no ambiente de trabalho}

Com base nas atitudes elencadas na Tabela 1, os respondentes atribuíram valores dentro da escala apresentada, de acordo com sua percepção quanto à Frequência dessas condutas de assédio moral no ambiente de trabalho.

Tabela 1 - Percentual de respostas para os itens da questão 1

\begin{tabular}{lccccc}
\hline \multicolumn{1}{c}{ Atitudes } & Nunca & $\begin{array}{c}\text { Quase } \\
\text { Nunca }\end{array}$ & $\begin{array}{c}\text { Às } \\
\text { Vezes }\end{array}$ & $\begin{array}{c}\text { Quase } \\
\text { sempre }\end{array}$ & Sempre \\
\hline $\begin{array}{l}1-\text { Críticas ao trabalho de forma } \\
\text { injusta ou exagerada. }\end{array}$ & $3,30 \%$ & $13,30 \%$ & $33,30 \%$ & $33,30 \%$ & $16,70 \%$ \\
$\begin{array}{l}2-\text { Omissão de informações úteis para } \\
\text { realização das tarefas de trabalho. }\end{array}$ & $3,30 \%$ & $20 \%$ & $30 \%$ & $30 \%$ & $16,70 \%$ \\
$\begin{array}{l}\text { - Violência verbal (xingamentos, } \\
\text { humilhações, uso de expressões } \\
\text { pejorativas). }\end{array}$ & $6,70 \%$ & $33,30 \%$ & $30 \%$ & $13,30 \%$ & $16,70 \%$ \\
$\begin{array}{l}4 \quad \text { Comportamento de desprezo } \\
\text { (isolamento, ignorar presença, não } \\
\text { cumprimentar) entre pares ou chefia. }\end{array}$ & $6,70 \%$ & $26,70 \%$ & $36,70 \%$ & $16,70 \%$ & $13,30 \%$ \\
$\begin{array}{l}5-\text { Privação dos instrumentos de } \\
\text { trabalho (telefone, computador, } \\
\text { mesa, etc.). }\end{array}$ & $23,30 \%$ & $10 \%$ & $30 \%$ & $26,70 \%$ & $10 \%$ \\
$\begin{array}{l}6 \quad \text { Atribuição de tarefas } \\
\text { incompatíveis com o cargo. }\end{array}$ & $6,70 \%$ & $20 \%$ & $20 \%$ & $36,70 \%$ & $16,70 \%$ \\
\end{tabular}


7- Discriminação quanto à cor, gênero, orientação sexual, convicções políticas e religião.

8- Violência psicológica (insinuações de doença mental, boatos sobre a vida privada) entre pares ou chefia.

9- Dificultar o exercício dos Direitos (férias horários, promoções) pela hierarquia superior.

\begin{tabular}{ccccc}
$20 \%$ & $30 \%$ & $33,30 \%$ & $10 \%$ & $6,70 \%$ \\
\hline $6,70 \%$ & $20 \%$ & $23,30 \%$ & $20 \%$ & $30 \%$ \\
$10 \%$ & $10 \%$ & $40 \%$ & $26,70 \%$ & $13,30 \%$ \\
& & & & \\
$13,30 \%$ & $16,70 \%$ & $6,70 \%$ & $43,30 \%$ & $20 \%$
\end{tabular}

10- Imposição de sobrecarga de trabalho por parte da chefia imediata.

Fonte: Dados de pesquisa (2016).

Conforme os dados apresentados, observou-se que nenhuma das frequências propostas obteve percentual superior ou igual a $50 \%$, denotando, com isso, que as atitudes de assédio moral não tendem para uma frequência alta na escala de valores.

A distribuição das respostas ao longo da maioria das atitudes de assédio moral apresentadas se concentra nas respostas quase nunca; às vezes e quase sempre, com percentuais que variam entre 26,7 a $43,33 \%$.

Atitudes cujas respostas tiveram percentuais maiores, respectivamente, nas respostas às vezes e quase sempre referem-se a:

- Críticas ao trabalho de forma injusta (ambos 33,3\%);

- Omissão de informações úteis (ambos 30\%);

- Privação dos instrumentos de trabalho (30\% e $26,7 \%)$;

- Dificultar o exercício dos Direitos (40\% e 26,7\%).

Essas atitudes, na percepção dos participantes da pesquisa, acontecem com certa frequência no ambiente de trabalho, confirmando a visão de autores sobre alguns comportamentos que tipificam o assédio moral no ambiente do trabalho, por sua intencionalidade, repetição e temporalidade (HIRIGOYEN, 2009b; SOBOLL; GOSDAL, 2009).

Ressalta-se que a atitude de privação dos instrumentos de trabalho também foi percebida com frequência nunca $(23,3 \%)$ para alguns participantes. Isso demonstra uma variação de percepção dos participantes da pesquisa quanto a essa conduta de assédio moral, que pode se manifestar mais vezes ou nunca acontecer no ambiente de trabalho.

Os dados de pesquisa indicaram que as atitudes, além daquelas supracitadas, com maiores percentuais da Frequência às vezes foram:

- Violência verbal (30\%);

- Comportamento de desprezo (36,7\%);

- Discriminação quanto à cor, gênero, orientação sexual, convicções políticas e religião (33,3\%);

- Violência psicológica (23,3\%).

Essas atitudes são nocivas, porque atentam contra a dignidade da pessoa do trabalhador, além de ser um obstáculo para o exercício pleno dos direitos fundamentais, conforme a Constituição Federal Brasileira (BRASIL, 1988) e Guedes (2008).

Vale, ainda, enfatizar que a violência psicológica foi percebida como a atitude que se manifesta com mais frequência, ou seja, sempre acontece no ambiente de trabalho (30\%). Considera-se que esse tipo de atitude no ambiente de trabalho depende da subjetividade do 
assediado, que pode percebê-la de modo mais intenso, dependendo das suas condições psicológicas para encarar as situações de estresse e mal-estar no trabalho.

Verificou-se que a atribuição de tarefas incompatíveis com o cargo, além de críticas ao trabalho de forma injusta; omissão de informações úteis e privação dos instrumentos de trabalho foram consideradas atitudes que se manifestam com bastante frequência, ou seja, elas acontecem quase sempre no ambiente de trabalho.

\section{Impacto das práticas de assédio moral no ambiente de trabalho}

O impacto do assédio moral sobre o ambiente organizacional foi averiguado na Tabela 2 , onde os respondentes atribuíram valores dentro da escala Likert proposta, conforme sua percepção do grau de impacto das atitudes de assédio moral.

Tabela 2 - Percentual de respostas para os itens da questão 2

\begin{tabular}{|c|c|c|c|c|c|}
\hline Atitudes & $\begin{array}{l}\text { Muito } \\
\text { alto }\end{array}$ & Alto & Médio & Baixo & $\begin{array}{l}\text { Muito } \\
\text { baixo }\end{array}$ \\
\hline $\begin{array}{l}1 \text { - Críticas ao trabalho de forma } \\
\text { injusta ou exagerada. }\end{array}$ & $40 \%$ & $40 \%$ & $13,3 \%$ & $6,7 \%$ & $0 \%$ \\
\hline $\begin{array}{l}2 \text { - Omissão de informações úteis para } \\
\text { realização das tarefas de trabalho. }\end{array}$ & $43,3 \%$ & $46,7 \%$ & $3,3 \%$ & $3,3 \%$ & $3,3 \%$ \\
\hline $\begin{array}{l}3 \text { - Violência verbal (xingamentos, } \\
\text { humilhações, uso de expressões } \\
\text { pejorativas). }\end{array}$ & $60 \%$ & $30 \%$ & $3,3 \%$ & $3,3 \%$ & $3,3 \%$ \\
\hline $\begin{array}{l}4 \text { - Comportamento de desprezo } \\
\text { (isolamento, ignorar presença, não } \\
\text { cumprimentar) entre pares ou chefia. }\end{array}$ & $46,7 \%$ & $26,7 \%$ & $16,7 \%$ & $6,7 \%$ & $3,3 \%$ \\
\hline $\begin{array}{l}5 \text { - Privação dos instrumentos de } \\
\text { trabalho (telefone, computador, } \\
\text { mesa, etc.). }\end{array}$ & $40 \%$ & $36,7 \%$ & $10 \%$ & $10 \%$ & $3,3 \%$ \\
\hline $\begin{array}{l}6 \quad \text { - Atribuição de } \quad \text { tarefas } \\
\text { incompatíveis com o cargo. }\end{array}$ & $23,3 \%$ & $56,7 \%$ & $10 \%$ & $10 \%$ & $0 \%$ \\
\hline $\begin{array}{l}\text { 7- Discriminação quanto à cor, } \\
\text { gênero, orientação sexual, convicções } \\
\text { políticas e religião. }\end{array}$ & $46,7 \%$ & $43,3 \%$ & $10 \%$ & $0 \%$ & $0 \%$ \\
\hline $\begin{array}{l}\text { 8- Violência psicológica (insinuações } \\
\text { de doença mental, boatos sobre a } \\
\text { vida privada) entre pares ou chefia. }\end{array}$ & $40 \%$ & $46,7 \%$ & $10 \%$ & $3,3 \%$ & $0 \%$ \\
\hline $\begin{array}{l}\text { 9- Dificultar o exercício dos Direitos } \\
\text { (férias horários, promoções) pela } \\
\text { hierarquia superior. }\end{array}$ & $20 \%$ & $40 \%$ & $23,3 \%$ & $16,7 \%$ & $0 \%$ \\
\hline $\begin{array}{l}\text { 10- Imposição de sobrecarga de } \\
\text { trabalho por parte da chefia imediata. }\end{array}$ & $33,3 \%$ & $56,7 \%$ & $6,7 \%$ & $3,3 \%$ & $0 \%$ \\
\hline
\end{tabular}

Fonte: Dados de pesquisa (2016).

Quanto ao impacto das atitudes de assédio moral no ambiente organizacional, observou-se que quase todas as atitudes obtiveram percentuais maiores nas respostas muito alto e alto, respectivamente: 
- Críticas ao trabalho de forma injusta ou exagerada (ambos 40\%);

- Omissão de informações úteis para realização das tarefas de trabalho $(43,3$ e $46,7 \%)$;

- Violência verbal (60 e 30\%);

- Comportamento de desprezo (46,7 e 26,7\%);

- Privação dos instrumentos de trabalho (40\% e 36,7\%);

- Atribuição de tarefas incompatíveis com o cargo (23,3\% e 56,7\%);

- Discriminação quanto à cor, gênero, orientação sexual, convicções políticas e religião (46,7 e 43,3\%).

- Violência psicológica (40 e 46,7\%);

- Imposição de sobrecarga de trabalho por parte da chefia imediata (33,3\% e 56,7\%)

Considera-se que as atitudes elencadas têm um impacto significativo no ambiente organizacional, sendo, portanto, atitudes merecedoras de mais atenção por parte dos gestores para mitigar, ou mesmo evitar, a deterioração do clima organizacional.

Dentre as atitudes com impacto muito alto nas organizações, destaca-se a violência verbal, que se manifesta sob a forma de xingamentos, humilhações, uso de expressões pejorativas, sendo, portanto, uma conduta que fere frontalmente a dignidade da pessoa humana, influenciando negativamente o ambiente organizacional.

Cabe ressaltar que a atitude Dificultar o exercício dos Direitos, apesar de ter maior percentual na resposta alto impacto (40\%), ou seja, tem impacto significativo no ambiente organizacional, também foi indicada como uma conduta com médio $(23,3 \%)$ e baixo $(16,7 \%)$ impacto nesse ambiente, tendo uma distribuição mais equilibrada nas respostas em relação às outras atitudes assediadoras.

Constatou-se que dados obtidos com esta pesquisa endossam a visão de autores como Ávila (2009) e Inácio (2012) que percebem as condutas assediadoras como fontes de degradação do clima organizacional, prejuízos para organização (imagem e indenizações trabalhistas). Não se pode deixar de lembrar, também, que a ocorrência do assédio moral está relacionada com o ambiente organizacional, os conflitos e a ambiguidade de papel, a sobrecarga de trabalho contínuo, a pressão no trabalho, a alta carga de trabalho mental, certos estilos de liderança e as formas de gestão (GARCíA-IZQUIERDO et al., 2014).

\section{Propostas de ações preventivas contra o assédio moral no ambiente de trabalho}

Conforme análise da questão aberta do questionário aplicado, identificaram-se as seguintes categorias de propostas para combater as manifestações do assédio moral no ambiente de trabalho:

- Esclarecimento de direitos e deveres para gestores e funcionários;

- Elaboração de políticas de gestão para apuração de denúncias de assédio moral e aplicação de punição para os assediadores;

- Adoção de canais abertos, com garantia de sigilo e segurança, para denunciar situações de assédio;

- Disseminação de conhecimento para esclarecer as chefias imediatas e superiores sobre os comportamentos que caracterizam e tipificam o assédio moral; 
- Gestão colegiada e participativa para combater o assédio moral no ambiente de trabalho;

- Elaboração de campanhas educacionais sobre o tema assédio moral;

- Criação de comissões compostas por advogados, psicólogos, administradores e representantes dos funcionários.

- Cumprimento dos códigos de ética e guia de conduta;

Destacam-se algumas respostas sobre o assédio moral e a forma de combatê-lo no serviço público, fornecidas pelos participantes da pesquisa e identificadas conforme as áreas de atuação:

No caso particular do Serviço Público, no qual se relata um sem-número de situações de servidores descomprometidos com a função pública, uma forma de defesa tem sido a alegação por esses servidores, de estarem sofrendo assédio moral. [...] Diante disso, é muito difícil sugerir o que fazer para combater o assédio moral, ao menos, como vejo, em meu contexto organizacional. Talvez um passo atrás possa ser dado em relação à verdadeira aplicação de punições ao mau exercício do cargo público, destituindo-se a ideia de que a estabilidade no Serviço Público admite condutas comportamentais irresponsáveis, descomprometidas e desqualificadas de servidores públicos [...] (Engenharia de Produção).

A segurança da estabilidade do setor público muitas vezes faz com que a vitima exponha a situação de assédio, o mesmo não ocorrendo no setor privado pelo medo da exposição e demissão. Muitas vezes o assediado prefere perder seu emprego a expor situação vexatória, muitas vezes, não levada a sério por quem pode fazer algo (Direito).

Para os novos servidores que ingressam no serviço publico, é importante reforçar os seus direitos e deveres para que tenham noção do que pode ser cobrado ou exigido dos mesmos. Qualquer abuso ou conduta inapropriada dever ser denunciada [...] Para os servidores antigos, é recomendável treinamentos e dinâmicas para discutir situações que levam ao assédio moral, com a intenção de coibir essas condutas e procurar alternativas para os problemas existentes. Atitudes de assédio moral podem ser peculiares nos ambientes de trabalho, por isso, a necessidade de palestras para mostrar como o fenômeno prejudica o trabalho e a saúde do trabalhador, sendo ruim para o servidor e a instituição onde atua (Administração de Empresa).

O papel dos Recursos Humanos (RH) também foi enfatizado nas respostas dos especialistas, cabendo aos gestores desse setor a elaboração de medidas e estratégias para lidar com situações de assédio moral e encaminhar soluções para os conflitos gerados. Nesse sentido, propõe-se:

Criar no departamento de RH um órgão competente para dar apoio em casos de assédio moral, com poder para estudar os casos e propor soluções; ao mesmo tempo, desenvolver padrões de liderança positiva, isto é, aberta às propostas dos colaboradores, preocupada em aproveitar suas 
competências, apostando no desenvolvimento desses colaboradores. Consolidar uma cultura de transparência e de verdade em toda a instituição (Administração de Empresa).

Uma das formas de combater o assédio moral seria através de uma ouvidoria interna anônima que a pessoa ou um pequeno grupo de pessoas (preferencialmente dos Recursos Humanos/Gestão de Pessoas) tenha acesso; com isso, é possível mapear quantidade e o que está acontecendo para poder tomar medidas reais e práticas contra o problema (Serviço Social).

Capacitar os profissionais de RH através da comprovação de que este poderá ser mais um dos caminhos capazes de contribuir para a condução dos objetivos estratégicos das organizações, contribuindo para a geração de mudança, riqueza e valor (Comunicação Social).

O apoio de sindicatos também foi mencionado por especialistas como sendo importante para dar apoio aos assediados e cobrar medidas preventivas junto às organizações com relação ao assédio moral no trabalho.

Quanto ao aspecto jurídico, ressaltou-se a dificuldade em apresentar provas de assédio moral, embora a punição exista na esfera cível e trabalhista, fato que foi enfatizado na seguinte resposta: "os assediadores não se importam de cometer o assédio, pois sabem da dificuldade de provar na justiça; as testemunhas por mais que saibam do ocorrido e da sua razão temem represálias, demissões se depuserem a favor do assediado" (Pedagogia). 0 assediador utiliza-se do horror causado em seu alvo. Além de intimidar a todos quebra o princípio de solidariedade fazendo com que sua vítima seja punida pelo assédio e pelo abandono dos demais.

Observaram-se também alguns relatos de situações vivenciadas de assédio moral pelos especialistas, assim descritas:

O assediador denigre a imagem da pessoa, humilha, pisa, ameaça, acaba com a dignidade da pessoa e estes comportamentos levam o assediado a cometer suicídio, à depressão, ansiedade, síndrome do pânico, síndrome de burnout, etc... Deixa o assediado inseguro, com medo, impede seu crescimento profissional, sua vida social, familiar, acaba com casamentos, leva a pessoa para o buraco (Psicologia).

Como parte envolvida emocionalmente é complicado escrever. Hoje, ainda somos muito imaturos nas grandes empresas, pois se reclamamos, somos remanejados, retirados dos locais de origem de trabalho, somos marcados e taxados como as encrencas (Pedagogia).

As respostas obtidas na questão aberta demonstraram como o fenômeno do assédio moral tem se manifestado nas organizações, demandando ações preventivas que protejam a saúde do trabalhador e garantam um clima organizacional saudável e propício ao desenvolvimento organizacional. 


\section{CONSIDERAÇÕES FINAIS}

Durante a pesquisa, comprovou-se que o tema do assédio moral no trabalho ainda é tabu para muitas pessoas. Verificou-se resistência ou dificuldade em responder às questões referentes ao tema, abordadas por meio do instrumento de pesquisa, conforme observado em algumas respostas obtidas. Foi dado importante, pois sinaliza o quanto as pessoas não são sinceras em relação ao assunto ou tem medo de se comprometer.

Ao enviar os questionários para os administradores de grupos fechados nas redes sociais, o retorno das respostas, no entanto, foi além do esperado com relação ao conteúdo das respostas. Algumas pessoas responderam e ainda citaram como sofreram o assédio e o quanto isso impactou e ainda impacta em sua vida. Alguns, através dessa experiência ruim, tornaram-se defensores da divulgação desse tema na tentativa de alertar outras vítimas. Isso corrobora com a literatura que demonstra o quanto esse mal é dissimulado, subjetivo e sorrateiro, sendo uma característica do assediado não conseguir tocar no tema sem aflição por rememorar o fato danoso. As técnicas de dominação e repressão pelo medo, aplicadas por muitos gestores, acompanham aquele trabalhador mesmo após sua saída do emprego. Dependendo da forma como o assédio foi entendido pelo indivíduo a sensação de injustiça, desrespeito, abandono pode ser irreversível. Muitas vezes, o trauma psíquico não permite tentativa de novo emprego.

No âmbito jurídico, crescem as reclamações sobre assédio moral no trabalho. Após a demissão, muitos trabalhadores rompem o silêncio talvez na tentativa de superação do possível trauma já que não existe possibilidade de ressarcimento financeiro diante do dano sofrido. Os que recorrem à justiça ainda contam com grande dificuldade para obtenção de prova testemunhal, pois as testemunhas muitas vezes estão na vigência de seus contratos de trabalho.

A revisão de literatura a nível internacional também demonstrou a importância do tema do assédio moral, bem como as formas de prevenção e tratamento desse fenômeno no ambiente organizacional.

É oportuno salientar que existem inúmeros tratados e pactos internacionais que foram ratificados pelo Brasil. Portanto, não falta fundamento jurídico para coibir a prática do assédio. $O$ que talvez falte é a cultura do respeito que deve pautar as condutas das relações humanas, não só sociais como no ambiente de trabalho.

Os gestores já não podem mais ignorar o problema e precisam rever alguns métodos de gestão, incluindo entre eles o esclarecimento do assunto como método de prevenção e, evitando assim, o uso do termo de forma equivocada.

\section{Contribuições futuras}

Tendo em vista a participação e contribuição de servidores públicos em número maior comparados à iniciativa privada nessa pesquisa, recomenda-se a realização de estudos futuros que enfoquem a questão do assédio moral em determinadas áreas de atuação no serviço público como: universidades, unidades de saúde, dentre outros.

$\mathrm{Na}$ iniciativa privada ainda nos deparamos com o triste fato do empregado temer ser dispensado de seu trabalho, caso denuncie o assédio. Dessa forma, temos dificuldades em aprofundamento de pesquisa específica. 
Considera-se que o objetivo desse estudo foi atingido, porém não se pode afirmar quais são os impactos nas organizações. Isso demanda uma continuidade de estudo, indo além das percepções e, com isso, identificar, de fato, o quanto as organizações sofrem impactos negativos quanto à imagem, financeiramente, entre outros aspectos.

É importante destacar que o assunto está longe de ser esgotado, pelo contrário, a discussão é ampla e multidisciplinar, envolvendo toda a sociedade, pois a todos interessa uma vida profissional saudável e digna. O assédio moral é uma conduta reprovável e deve ser combatida.

\section{REFERÊNCIAS}

AGENDA Nacional de Trabalho Decente. Brasília, 2006. Disponível em: <http://www.oit.org.br/sites/default/files/topic/decent_work/pub/agenda_nacional_trabal ho_decente_298.pdf>. Acesso em: 05 fev. 2015.

ALKIMIN, M. A. Assédio moral na relação de emprego. Curitiba-PR: Juruá, 2005.

ARAÚJO, A. R. O Assédio Moral Organizacional. São Paulo: LTr, 2012.

ÁVILA, R. P. As consequências do assédio moral no ambiente de trabalho. São Paulo: LTr, 2009.

BRANCH, S.; RAMSAY, S.; BARKER, M. Workplace bullying, mobbing and general harassament: a review. International Journal of Management Reviews, v. 15, p. 280-299, 2013.

BRASIL. Consolidação das Leis Trabalhistas. 4. ed. atual e amp. Vade Mecum. São Paulo: Saraiva, 2007.

Disponível Constituição Federal (1988). Constituição da República Federativa do Brasil. <http://www.planalto.gov.br/ccivil_03/constituicao/ConstituicaoCompilado.htm>. Acesso em: 25 out. 2015.

CALVO, A. O direito fundamental à Saúde mental no ambiente de trabalho: o combate ao assédio moral institucional: visão dos tribunais trabalhistas. São Paulo: LTr, 2014.

CARNERO, M. A.; MARTÍNEZ, B.; SÁNCHEZ-MANGAS, R. Mobbing and workers'health: empirical analysis for Spain. International Journal of Manpower, v. 33, n. 3, p. 322-339, 2012.

CONVENÇÃO Americana de Direitos Humanos (1969) (Pacto de San José da Costa Rica). Disponível em: <http://www.pge.sp.gov.br/centrodeestudos/bibliotecavirtual/instrumentos/sanjose.htm>. 24 out. 2015. 
FAULX, D.; BLAVIER, A. Developing a multiple-level, multiple-perspective and multi-temporal approach to psychological harassament at work: model and case study. Le travail humain, $v$. 76, n. 2, p. 155-179, 2013.

FIGUEIREDO-FERRAZ, $\mathrm{H}$. et al. Influence of some Psychosocial factors on mobbing and its consequences among employees working with people with intellectual disabilities. Journal of Applied Research in Intellectual Disabilities, 25, p. 455-463, 2012.

GARCÍA-IZQUIERDO, M. et al. Advances in the study of bullying at work. Papeles del Psicólogo, v. 35, n. 2, p. 83-90, 2014.

GIL, A.C. Métodos e técnicas de pesquisa social. 5. ed. São Paulo: Atlas, 1999.

GIORGI, G. et al. Exploring personal and organizational determinants of workplace bullying and its prevalence in a Japanese Sample. American Psychological Association, v. 3, n. 2, p. 185-197, 2013.

GUEDES, M. N. Terror psicológico no trabalho. 3. ed. São Paulo: LTr, 2008.

HIRIGOYEN, M. F. Assédio Moral: A violência Perversa do Cotidiano. 11. ed. Rio de Janeiro: Editora Bertrand do Brasil, 2009a.

. Mal-estar no Trabalho, redefinindo o Assédio Moral. 4. ed. Rio de Janeiro: Editora Bertrand do Brasil, 2009b.

INÁCIO, A. Assédio Moral, Discriminação, Igualdade e Oportunidades no Trabalho. São Paulo: LTr, 2012a.

Assédio Moral no mundo do trabalho. São Paulo: Ideias \& Letras, 2012b.

MARCONI, M. A.; LAKATOS, E. M. Fundamentos de Metodologia Científica. 7. ed. São Paulo: Atlas, 2010.

MESEGUER, M.; SOLER, M. I.; GARCÍA-IZQUIERDO, M. El papel moderador de la autoeficacia profesional entre situaciones de acoso laboral y la salud en una muestra multiocupacional. Anales de Psicologia, v. 30, n. 2, p. 573-578, mar. 2014.

MOLÉ, Noelle J. Precarious subjects: anticipating neoliberalism in Northern Italy's workplace. American anthropologist, v. 112, iss. 1, p. 38-53, 2010.

NASCIMENTO, S. O Assédio Moral no Ambiente de Trabalho. Revista LTr, São Paulo, v. 68, n. 08, p.922-930, agosto. 2004.

Assédio Moral e Dano Moral no Trabalho. 3. ed. São Paulo: LTr, 2015.

NEALL, A. M.; TUCKEY, M. R. A methodological review of research on the antecedents and consequences of workplace harassment. Journal of Occupational and Organizational Psychology, v. 87, p. 225-257, 2014. 
ORGANIZAÇÃO DAS NAÇÕES UNIDAS. Documento oficial Declaração Universal dos Direitos do Homem. Unidos pelos Direitos Humanos. 1948. Disponível em: http://www.humanrights.com/pt/what-are-human-rights/universal-declaration-of-humanrights/articles-21-30.html. Acesso em: 25 out. 2015.

ORGANIZAÇÃO INTERNACIONAL DO TRABALHO. Discriminação em Matéria de Emprego e Ocupação (Convenção n. 111). 1958. Disponível em: http://www.oit.org.br/node/472. Acesso em: 25 out. 2015.

- Convenção sobre segurança e saúde dos trabalhadores (Convenção n. 155). 1981. Disponível em: http://www.oitbrasil.org.br/node/504. Acesso em: 25 out. 2015.

ORGANIZACIÓN MUNDIAL DE LA SALUD. Sensibilizando sobre El acoso psicológico em EI trabajo. Série Protección de La Salud de los Trabajadores, 4, Genebra, 2004.

PACTO Internacional dos Direitos Econômicos, sociais e culturais. 1992. Disponível em: < http://www.planalto.gov.br/ccivil_03/decreto/1990-1994/D0591.htm>. Acesso em: 24 out. 2015.

PAROSKI, M. V. Assédio moral no trabalho. Jus Navigandi, Teresina, ano $11, \mathrm{n}$. 1196, 10 out. 2006. Disponível em: <http://jus.com.br/artigos/9021>. Acesso em: 14 jul. 2015.

PARREIRA, A. Assédio Moral: um manual de sobrevivência. Campinas: Russell, 2007.

RICHARDSON, J. R. Pesquisa Social: métodos e técnicas. 3. ed. São Paulo: Atlas, 1999.

SHALLCROSS, L.; RAMSAY, S.; BARKER, M. Severe workplace conflict: the experience of mobbing. Negociation and conflict management research, v. 6, n. 3, p. 191-213, 2013.

SOBOLL, L. A. P. Violência psicológica e assédio moral no trabalho. São Paulo: Casa do Psicólogo, 2006.

; GOSDAL, T. C. (Org.). Violência psicológica e assédio moral no trabalho. São Paulo: Casa do Psicólogo, 2009.

SOUZA, J. D. As chefias avassaladoras, assédio moral. São Paulo: Novo Século, 2009. 